\title{
Can reference points explain wage rigidity? Experimental evidence
}

\author{
Christian Koch ${ }^{*}$ (1)
}

\begin{abstract}
I examine whether reference points can provide an explanation for rigid wages in recessions. Even though a recession provides a good reason to adjust wages downward, workers' perception of a "fair wage" may depend on their previous wage, their reference point. Using a laboratory experiment, I test this idea by varying whether initially concluded contracts - and their stipulated wages — can serve as reference points. My experimental results show that with initial contracts workers punish wage cuts even in recessions, leading to considerable more rigid wages. Surprisingly, this is even true without an "objective" justification to feel entitled to initial contracts.
\end{abstract}

Keywords: Wage rigidity, Reference points, Gift exchange, Labor contracts, Experiments

JEL classification: $\mathrm{C} 9, \mathrm{~J} 3, \mathrm{M} 5$

\section{Introduction}

A long-standing question in economics is why wages do not fall in recessions (Fehr and Goette 2005; Bauer et al. 2007; Dickens et al. 2007). Understanding this phenomenon of (downward) wage rigidity is important as it has been shown empirically to be associated with unfavorable labor market outcomes, in particular unemployment (Barwell and Schweitzer 2007; Devicienti et al. 2007; Elsby et al. 2016). A number of explanations of why firms pay wages that are above the market clearing wage and that cannot be easily adjusted downward has been put forward, including e.g. insider-outsider theories (Lindbeck and Snower 1988, Calmfors and Driffill 1988) or (disciplining versions of) the efficiency wage hypothesis (Gintis 1976; Shapiro and Stiglitz 1984). ${ }^{1}$

This study's focus will be on a fairness explanation of the wage rigidity puzzle that has found support by questionnaire studies interviewing managers (e.g. Blinder and Choi 1990; Campbell and Kamlani 1997; Bewley 1999): When contracts are incomplete, firms partly have to rely on workers' intrinsic motivation and their fairness

${ }^{*}$ Correspondence: chris.koch@univie.ac.at

Department of Economics, University of Vienna, Oskar-Morgenstern-Platz 1, 1090 Vienna, Austria concerns. Wage cuts are, however, perceived as unfair by workers and lead to a decrease in work morale. In anticipation, firms do not cut wages.

But why do workers perceive wage cuts as unfair even though a recession seems to provide an appropriate reason to cut wages since it limits firms' abilities to pay high wages? Even standard outcome-based fairness models (e.g. Fehr and Schmidt 1999; Charness and Rabin 2002) predict moderate wage cuts since they enable fairminded workers to share the recession's burden that otherwise only the firm would have to bear. Already Akerlof (1982) and Akerlof and Yellen (1990) have suggested, however, that what workers perceive as a "fair wage" might depend-among other things ${ }^{2}$ - on the wage they previously received, their reference point (Goette et al. 2007; Shafir et al. 1997). While this seems very plausible

\footnotetext{
${ }^{1}$ Other theories of wage rigidity include the implicit contract theory (as developed by Baily 1974; Gordon 1974; Azariadis 1975) or job search models as reviewed in Mortensen (1986).

${ }^{2}$ Akerlof (1982) have also highlighted the importance of social comparisons for the "fair wage", namely what co-workers earn. This study focuses on past wages, but other work has already explored the social comparisons (see e.g. Charness and Kuhn 2007; Abeler et al. 2010; Bartling and von Siemens 2011; Cohn et al. 2014). Recent studies (Charness et al. 2012; Franke et al. 2016) have also explored workers' participation in wage setting as an influence on workers' fairness perceptions and effort provision.
}

\section{Springer Open}

(c) The Author(s) 2021. This article is licensed under a Creative Commons Attribution 4.0 International License, which permits use, sharing, adaptation, distribution and reproduction in any medium or format, as long as you give appropriate credit to the original author(s) and the source, provide a link to the Creative Commons licence, and indicate if changes were made. The images or other third party material in this article are included in the article's Creative Commons licence, unless indicated otherwise in a credit line to the material. If material is not included in the article's Creative Commons licence and your intended use is not permitted by statutory regulation or exceeds the permitted use, you will need to obtain permission directly from the copyright holder. To view a copy of this licence, visit http://creativeco mmons.org/licenses/by/4.0/. 
under stable conditions, it is less clear whether it is also true in a recession.

In this study, I experimentally manipulate whether (previous) out-of-recession wages can serve as a reference point, influence what workers perceive as a "fair wage" in recession and, thereby, provide an explanation for rigid wages. In an informative field experiment, Kube et al. (2013) have already shown that exogenous wage cuts have a negative impact on participants' work morale. Crucially, the authors deliberately cut wages without providing a "good reason" (e.g. recession), and Chen and Horton (2014) - although using a fairly different settingdo not find a negative effect when providing such an explanation. Since significant company-wide wage cuts are rarely observed, empirical evidence is scarce. For the airline industry, Lee and Rupp (2007) find only limited support that wage cuts lower employee effort. A potential explanation is that most of the wage cuts they observe occur under the threat of bankruptcy, providing a justification for the cut. Finally, Bracha et al. (2015, p. 312) have experimentally shown that making a given wage high (or low) relative to past or other wages increases (decreases) labor supply. Crucially, the authors find that providing "even a flimsy rationale" for these differences make the effect disappear. ${ }^{3}$

Although there is, thus, evidence that previous wages can serve as reference points, precisely this evidence cast doubts on whether this is actually true under all circumstances, questioning whether a fairness explanation of wage rigidty is valid for the recession case. Questionnaire and survey studies (Kahneman et al. 1986; Charness and Levine 2002; Kaur 2018) might be consistent with this idea but cannot-due to a lack of control treatments-rule out that wage cuts are rejected for reasons unrelated to reference points: If workers believe that it is the firm that mostly benefits from a boom, they might be generally unwilling to share the burden of the bust because they might perceive the recession as part of the firm's entrepreneurial risk, completely independent of reference points. Utilizing the strength of the experimental analysis, I test, under tightly controlled conditions, whether one particular explanation of wage rigidity-a

\footnotetext{
${ }^{3}$ There is additional evidence that reference points and previous wages influence current wages, which is, however, not directly related to rigid wages in recessions. Abeler et al. (2011) have experimentally shown that expectations affect workers' reference points. Accordingly, Mas (2006) find empirical evidence that wage increases that do not meet workers' expectations can lead to a decline in performance. Similarly, Ockenfels et al. (2015) show that managers' performance is reduced when their bonus payment falls behind a reference point (see also Cohn et al. 2015). Notably, these papers do not illuminate whether a "good" reason (recession) provides a justification for wage cuts. Falk et al. (2006) have shown experimentally that reservation wages are influenced by the introduction of minimum wages (see also Owens and Kagel 2010). Finally, Greenberg (1990) and Greenberg (1993) find evidence that underpayment can lead to theft.
}

fairness explanation (potentially in combination with reference points)-is valid even in times of recession. This is my paper's core contribution. The main innovation of my design is to manipulate whether out-of-recession wages can serve as reference points inspired by the idea of Hart and Moore (2008) that contracts serve as reference points (see also Herweg and Schmidt 2015). In "real-world" labor markets, contractual arrangements often have to be revised before wage cuts can be implemented. In such a revision, existing contract conditions might be salient and, thus, serve as reference points.

I model the labor market as a simple gift-exchange (Fehr et al. 1993). Firms sometimes face a 'recession'-in terms of a negative profit shock-that ceteris paribus only reduces their profits. Two different treatments manipulate whether (previous) out-of-recession wages can serve as reference points. In the Contracts as Reference Points (CasRP) treatment, workers and firms first conclude a contract before they are informed about whether a recession has occurred in this period. In the recession case, the concluded contract can be revised. Otherwise, initial contract conditions determine payoffs. In this treatment, the initial contract's wage-which workers explicitly agreed to when accepting a contract offer-potentially serves as a reference point for the revision stage. Implementing such a contract-revision structure deviates from much of the prior literature but provides out-of-recession wages with a realistic shot at serving as reference points. This is not possible in the Baseline (BASE) treatment. Here, firms and workers are first informed about whether a recession has occurred and only afterwards have the ability to conclude a contract. Hence, firms' contract offers can already take the state of the world into account and no initial contracts exist.

The data suggests that wages are neither completely rigid $^{4}$ in CasRP nor in BASE. Wage cuts ${ }^{4}$ are, however, significantly higher in BASE than in CasRP. Compared to the out-of-recession case, the average wage is reduced by 13.1 points (or 21 percent) in recession in BASE but less than half this amount (6.0 points or 10 percent) in CasRP. In the latter treatment, there is evidence of a referencepoint effect: Controlling for the wage level, workers' effort is lower for wages below the reference wage compared to those at or above this level. This, reference-point effect leads to significant treatment differences: In case wages are cut in CasRP, workers do not share the recession's burden (as much) as they do in BASE, explaining why firms pay more rigid wages in CasRP.

\footnotetext{
${ }^{4}$ It seems reasonable to use the terms rigid wages and wage cuts also for BASE. Crucially, due to construction, they can, however, only refer to a comparison of average wages in and out of recession in BASE.
} 
On the basis of these results, I implemented two control treatments. First, the Wages as Reference Points (WasRP) treatment shows that an "objective" justification for feelings of entitlement-an explicit contract agreement-is surprisingly not necessary to induce more rigid wages, highlighting a strength of reference points that has not been observed in previous studies. Second, the Contract as Reference Points treatment with Feedback (CasRP-F) manipulates the firm's information condition by providing better feedback but does not lead to significant differences, at least on average.

Overall, this study provides evidence that is consistent with the idea that reference points shape what workers perceive as a "fair" recession wage in a controlled experimental labor market, providing one explanation for more rigid wages in this setting. My paper may also help to reconcile conflicting results in the experimental literature linked to wage rigidity. As noted before, my study focuses on the revision of contractual arrangements that make reference points salient. In contrast, the earlier literature was primarily concerned with reactions to wage changes relative to earlier periods, where every period featured a "new contract". In the latter setting, earlier contracts seemed not serve as reference points and Burda et al. (2005), Kocher and Strasser (2011), and Gerhards and Heinz (2017) find that wages are flexible. In contrast, Hannan (2005) uses a setting in which initial wages are revised in recession and workers at least partly seem to punish wage cuts. Notably, since her study does not focus on wage rigidity, it misses control treatments, and it is even unclear how rigid wages overall are in her setting. Finally, Buchanan and Houser (2020) investigate wage rigidity in a setting in which contracts can serve as reference points but do not provide a control treatment in which this is not the case as they focus on employers' beliefs about workers' work morale and the distinction between nominal and real wage cuts. My study, thus, complements their research.

This study also informs the literature about contracts as reference points, starting with Hart and Moore (2008). Unrelated to wage rigidity, their model mainly analyzes why people write long-term employment contracts by looking at the implications of reference points for different contract types. Fehr et al. (2009, 2011, 2015) experimentally test these implications comparing the performance of different contract types. Bartling and Schmidt (2014) are the first that analyze how initially concluded contracts affect renegotiation via reference-point formation in a buyer-seller relationship. While reference points in their setting constrain sellers to be fair and not to exploit buyers, they have a converse effect in my setting: they encourage workers not to share a part of the recession's burden by refusing to accept wage cuts and, thus, actually behave less fair-minded than otherwise

\section{Experimental design and procedures}

\subsection{Main Treatments: BASE vs. CasRP}

I consider an experimental labor market in which firms can be hit by a 'recession' (see Kocher and Strasser 2011 and Gerhards and Heinz 2017). More precisely, following Fehr et al. (1993), I model the labor market as a simple gift-exchange but modify the standard setting by using a non-static version in which firms can be randomly hit by a negative profit shock (which is called a "bad market situation" in the instructions). Notably, for the ease of exposition, I use the terms 'negative profit shock' and 'recession' interchangeably in the following, but the reader should always bear in mind the stylized nature of the 'recession' in my setting, as outlined below. The game proceeds as follows: Firms make a contract offer by choosing a wage, an integer $w \in\{30, \ldots, 100\}$, and workers who accept a contract offer have to choose how much effort to exert, $e \in\{1, \ldots, 10\}$.

As usual in a gift-exchange setting, contracts are incomplete since workers' effort levels are not contractable. I implemented a slightly modified version of the payoff functions used by Riedl and Tyran (2005). Firms have the following payoff function:

$$
\Pi_{F}=\left\{\begin{array}{l}
10 \times e-w+50, \text { if no profit shock occurs }\left(p=\frac{2}{3}\right), \\
10 \times e-w+30, \text { otherwise }\left(p=\frac{1}{3}\right) .
\end{array}\right.
$$

Workers' payoffs are given by

$$
\Pi_{W}=w-c(e) .
$$

Here, $F$ denotes the firm, $W$ denotes the worker, and $c(e)$ is the cost of effort that is an increasing function of $e$. In my experiment, I used a standard cost-of-effort function shown in Table 1. Workers who reject their contract offer get a payoff of $\Pi_{W_{0}}=20$ whereas their assigned firms get a zero profit, $\Pi_{F_{0}}=0$. Additionally, firms earn zero profits if their contract offers have been accepted, but effort levels had resulted in a negative payoff for the firm. Notably, firms do not state a desired effort level. For clean identification, only one variable-the wage-will potentially serve as a potential reference point in my setting.

My payoff functions capture the following core idea: In a recession, first of all only firms suffer. The question then is whether workers are willing to share a part of the recession's burden. More particularly, these functions were chosen to meet two objectives: The impact of a recession should be substantial enough such that firms consider cutting wages, but at the same time firms that do not cut 
Table 1 Effort levels and cost of effort

\begin{tabular}{lllllllrrrr}
\hline$e$ & 1 & 2 & 3 & 4 & 5 & 6 & 7 & 8 & 9 & 10 \\
$\mathrm{c}(\mathrm{e})$ & 0 & 1 & 2 & 4 & 6 & 8 & 10 & 12 & 15 & 18 \\
\hline
\end{tabular}

wages should still make a small profit or at least avoid losses. The underlying idea is that questionnaire studies (see e.g. Bewley 1999, Kahneman et al. 1986) suggest that losses legitimize wage cuts: They find that firms that face losses in the field are able to reduce wages substantially and that the general wage-rigidity finding is driven by those firms that are not threatened in their existence. My design focuses on the latter situation. To avoid that losses legitimize wage cuts, firms are provided with some extra money (50 points) and it is ruled out that firms make negative earnings. ${ }^{5}$

In this setting, I implemented two main treatments that are designed to test whether out-of-recession wages can serve as reference points and, thus, influence what workers perceive as a fair wage in recession. My design is (loosely) based on the idea of Hart and Moore (2008) that contracts serve as reference points because they create feelings of entitlement. Wage cuts in "real-world" labor markets might require a revision of the contractual arrangements between workers and firms simply because these arrangements already exist before the recession. In particular, in the Contracts as Reference Points (CasRP) treatment, contracts concluded initially before recessions-or more precisely the initial out-of-recession wage they stipulate-can potentially serve as reference points for workers' feelings of entitlement regarding the recession wage. In the Baseline (BASE) treatment, no such initial contracts exist. For reasons of treatment comparability, a bilateral version of the gift-exchange game is implemented in both treatments: Subjects play in groups of 12 ( 6 firms and 6 workers) for 18 periods. ${ }^{6}$ One firm is matched with one worker and pairs are randomly rematched every period. This rematching is implemented to minimize the importance of reference points other than those induced by initially concluded contracts (e.g. previous periods). This allows for a clean identification of the impact reference points induced by initial contracts and their stipulated wages. Moreover, Fehr et al. (1998)

\footnotetext{
${ }^{5}$ Implementing the 'recession' by a reduction of the extra money by 20 points ensures that both objectives are met in a simple, feasible way for all wage levels: Independent of the out-of-recession wage level, firms experience a noticeable decrease of their profits in recession. This decrease is, however, still small enough not to inevitably lead to zero profits when wages are not reduced. Alternatively reducing the productivity parameter might be considered more realistic but has the drawback that both objectives cannot be easily ensured for all wage levels.

${ }^{6}$ Occassionally, there were also groups of 10 with 5 firms and 5 workers.
}

do not find significant differences between a bilateral version of the game and gift-exchange markets.

\subsubsection{CasRP treatment}

- Stage 1: Firms make a contract offer to their workers by choosing a wage, $w_{1} \in\{30, \ldots, 100\}$. Afterwards, these workers have to decide whether they want to accept their offer. If they accept, workers have to choose their effort level, $e_{1} \in\{1, \ldots, 10\}$. This effort level is first of all not communicated to firms. If they reject, subjects are informed about payoffs in stage 3.

- Stage 2: At the beginning of the second stage, two out of six firms are randomly selected and hit by a negative profit shock. ${ }^{7}$ Only these two firms are allowed to change the initial contract conditions by choosing a new wage, $w_{2} \in\{30, \ldots, 100\}$. Although affected workers cannot reject wage changes, they are allowed to adjust their initial effort by choosing a new effort level, $e_{2} \in\{1, \ldots, 10\}$.

- Stage 3: Firms and workers get to know their payoffs, and firms are informed about their workers' relevant effort if their contract offer has not been rejected. This means that firms only learn about $e_{1}$ in case a negative shock does not occur, and in case such a shock occurs, firms only learn about $e_{2}$, ensuring comparability with BASE.

In case that no profit shock occurs, wages and effort levels of stage $1, w_{1}$ and $e_{1}$, determine payoffs. Otherwise, wages and effort levels of stage $2, w_{2}$ and $e_{2}$, determine payoffs. In BASE, no initial contracts that could serve as a reference point exist and, thus, firms are informed upfront whether a negative profit shock has occurred.

\subsubsection{BASE treatmentBASE treatment}

- Stage 1: At the beginning of the first stage, two out of six firms are randomly selected. These two firms are hit by a negative profit shock. Knowing whether

\footnotetext{
${ }^{7}$ In my design, only some firms have to face a negative profit shock in each period and not all firms in some periods. Due to the bilateral structure, no qualitative differences should be observed. In both situations, workers and firms only have information about their wage and effort, not about other wages or effort levels. The outlined implementation was chosen because it is more appropriate for a potential follow-up study.
} 
they have been hit by such a shock or not, firms make a contract offer to workers by choosing a wage, $w \in\{30, \ldots, 100\}$.

- Stage 2: This stage depends on the previous one. In case the assigned firm is not hit by a negative profit shock, workers first have to decide whether they want to accept their contract offer or not. If they accept, workers have to choose their effort level, $e \in\{1, \ldots, 10\}$. In case the assigned firm is actually hit by a negative profit shock, workers only have to choose their effort but cannot reject the contract offer. This difference is implemented in order to ensure comparability with the CasRP treatment.

- Stage 3: Firms and workers get to know their payoffs, and firms are informed about their workers' effort if their contract offer has not been rejected.

In both treatments, subjects are informed about the exact sequence of events in advance. The fundamental idea of the two treatments is that in one of them initial contracts exist while this not true in the other. Notably, this implies that CasRP has two important features: First, even in case there is a profit shock, subjects know the wage without such a shock, which is not true in BASE. Second, they explicitly agreed to this latter wage. Although this seems to realistically capture field labor contracts, it also represents a change of two things at the same time. I conjectured that the acceptance decision would be necessary for contracts to serve as reference points and, hence, for observing wage rigidity. The underlying idea was that only an explicit agreement might sufficiently trigger workers' self-serving biases because only when such an agreement exists wage cuts can constitute a violation of it. My first control treatment (WasRP) will disentangle whether an acceptance is really necessary, allowing for a clean identification of the impact and the channel of reference points. Surprisingly, it will show that the acceptance decision is actually not necessary.

The contract revision in recession is implemented following Fehr et al. (2015). Firms can revise their worker's wage as they like and workers cannot get out of an agreed-upon contract and reject the new wagealthough they can change their effort level. This extreme implementation is not intended to capture field negotiations realistically but tries to provide "stress test" for contractual reference points. Previous studies' suggest that the impact of reference points can be limited by design specifics and Fehr et al. (2015, p. 4) have argued that "the easier it is to change a contract the less likely it is to serve as a reference point," biasing against observing any effect of reference points. In addition, alternative implementations ${ }^{8}$ that allow for rejections in recession are experimentally less feasible. ${ }^{9}$

Nonetheless, three concerns may arise. First, workers may perceive the revision procedure as especially aversive in CasRP because firms can change an established contract. Second, one may also fear that the asymmetry between the recession and the no-recession case is more salient and less natural in BASE (as there is no initial contract), creating an experimenter demand effect to lower wages in this treatment. Finally, providing an opportunity to reject a contract out-of-recession but not in recession might raise the concern that firms have to pay higher wages in case workers can reject. Crucially, my first control treatment, WasRP, has a structure that resembles BASE more closely-not featuring established contracts for example-and, hence, allows me to control for the first two concerns. The last concern, however, even biases against observing rigid wages in recession, suggesting that my analysis provides a conservative test for wage rigidity.

\subsection{Control treatments, discussion \& procedures}

In case a difference between BASE and CasRP is observed, the two control treatments try to illuminate why such a treatment difference is observed. The first control treatment is the Wages as Reference Points (WasRP) treatment. This treatment tries to disentangle which of the two main aspects changed from BASE to CasRP potentially provides a channel that leads to rigid wages. Is an explicit contract conclusion necessary to create workers' resistance against wage cuts or do contracts already serve as reference points just by determining the out-of-recession wage and conveying this information to workers? Concerning the sequence of events, this treatment is a combination of BASE and CasRP. Workers know the payoff-relevant outof-recession wage also in recession (and that this wage

\footnotetext{
${ }^{8}$ First, a real renegotiation stage in which the initial contract is valid in case workers reject wage changes would require a baseline treatment comparable to Bartling and Schmidt (2014): the same initial participants' behavior as in CasRP would have to be exogenously imposed in this baseline treatment. This would, of course, undermine the ability to analyze whether firms anticipate resistance against wage cuts in CasRP and already adjust out-of-recession wages downward compared to the baseline. By construction, initial behavior would be the same in both treatments. Second, when workers' rejection leads to outside-option payments, rejecting would only provide a reasonable expensive punishment opportunity for wage cuts that lead to very low but not to medium/high wage levels since outside-option payments are not too high. Rejecting e.g. a wage cut from 90 to 75 would lead to outside option payments of 30 , resulting in a cost of up to 45 points.

9 The result of the first control treatment-that an explicit acceptance is not necessary-suggests that a design without an acceptance decision at any point would also have led to rigid wages. Notably, due to its simplicity, this alternative design might be considered preferable to the implemented one. Crucially, this insight was, of course, only gained in hindsight: it materialized as a consequence of my more complex design and can, thus, be seen as a result of my analysis.
} 
Table 2 Summary of treatments

\begin{tabular}{llllcc}
\hline Treatments & $\begin{array}{l}\text { Information about out-of-recession } \\
\text { wage in recession }\end{array}$ & $\begin{array}{l}\text { Initial contracts (explicit } \\
\text { agreement) }\end{array}$ & $\begin{array}{l}\text { Extended } \\
\text { feedback }\end{array}$ & $\begin{array}{l}\text { Sessions } \\
\text { of subjects }\end{array}$ \\
\hline BASE & No & No & No & 6 & 68 \\
CasRP & Yes & Yes & No & 6 & 70 \\
WasRP & Yes & No & No & 6 & 68 \\
CasRP-F & Yes & Yes & Yes & 6 & 72 \\
\hline
\end{tabular}

Notes: While all treatments except BASE inform workers about the out-of-recession wage also in recession, initial contracts and, thus, an explicit agreement about the out-of-recession wage is only given in CasRP/CasRP-F but not in WasRP. Finally, firms are only provided with extended feedback in CasRP-F

potentially has been cut) although they have not explicitly concluded a contract with their firm before the recession. Because there is no explicit contract conclusion, WasRP is, however, structurally closer to BASE avoiding potential concerns outlined before.

- Stage 1: Firms choose a contract offer (by specifying a wage) for the case that no negative profit shock occurs. Then, the computer selects two out of six firms. These firms are hit by a negative profit shock and are allowed to adjust their contract offer for the recession.

- Stage 2: If the assigned firm is not hit by a negative profit shock, workers first have to decide whether they want to accept their (out-of-recession) contract offer or not. If they accept, they have to choose their effort. If the assigned firm is hit by a negative profit shock, workers only have to choose their effort but cannot reject their (recession) contract offer. Importantly, in the second case, workers are also informed about the out-of-recession contract offer (wage) that is irrelevant for payoffs.

- Stage 3: Firms and workers get to know their payoffs, and the firms are informed about their workers' relevant effort if their contract offer has not been rejected. ${ }^{10}$

My second control treatment is the Contracts as Reference Points treatment with Feedback (CasRP-F). This treatment is very similar to CasRP and only slightly varies the information condition of the firm. To ensure comparability between BASE and CasRP, firms are only informed about their workers' relevant effort levels (not about effort level adjustments) in stage 3 in CasRP. Hence, it is not straightforward for firms to infer how workers react to wage cuts. But if workers punish wage

\footnotetext{
${ }^{10}$ This treatment also controls for a small difference between the two main treatments: In CasRP, an out-of-recession wage offer can be rejected and in this case a potential recession cannot even occur, potentially creating a selection problem since this is not true for BASE. Although this type of rejection is empirically very rare (10 out of 630 cases) and would potentially bias against observing a treatment difference, it does not even exist in WasRP.
}

cuts and firms are not fully aware of this behavior, the difference between the BASE and the CasRP treatment might underestimate the real difference caused by initial contracts. In CasRP-F, however, firms in recession are informed not only about the relevant but about both effort levels in stage 3 . Table 2 provides an overview over all four treatments, summarizing the key differences.

Sessions lasted on average between 75 and 90 minutes and took place at the mLab at the University of Mannheim. Overall, 278 (undergraduate and master) student subjects (six session per treatment with 10-12 subjects) of any field participated in the experiment and earned on average 20 EUR, where final payoffs are the sum of all 18 periods' payoffs. Recruitment was done by ORSEE, Greiner (2004), and the experiment was programmed in $\mathrm{z}$-Tree (Fischbacher 2007). Experimental instructions-that had a labor-market framing to facilitate understanding-for all treatments can be found in the Additional file 1: Appendix E.

\section{Hypotheses}

In this section, I discuss two hypotheses. These hypotheses are based on the model of inequity aversion by Fehr and Schmidt (1999). I provide a simple extension of this model-inspired by the idea of Hart and Moore (2008) - that incorporates that workers' behavior might be reference-dependent with respect to the previous out-of-recession wage. ${ }^{11}$ In the text, I focus on providing intuitions, whereas Appendix A outlines more formal arguments. Crucially, the gift-exchange literature has shown that the standard game theoretic solution is not a good predictor for this game. ${ }^{12}$ Whether wage cuts happen in such an equilibrium is not really an empirically interesting question, and for this reason my design was not tailored to allow for such equilibrium wage cuts.

\footnotetext{
${ }^{11}$ See also Dickson and Fongoni (2019) for a more elaborated approach.

12 Assuming common knowledge of perfectly rational and selfish agents: Workers do not have an incentive to provide more than minimal effort, $e=1$ (even though the highest feasible effort level would maximize the joint surplus). Firms anticipate this and choose the minimum wage for workers, $w=30$. In recession, firms' and workers' behavior does not change because firms already pay the minimum wage. This outcome is the same for all treatments because material incentives do not change between treatments.
} 
Fairness models, however, predict participants' behavior in the gift-exchange game more accurately. If workers are sufficiently fair-minded/inequity-averse, they will reciprocate high wages by high effort levels, (ideally) splitting the surplus with their firm equally to avoid harming inequality. Since only the firm but not the worker is hit by a negative profit shock in recession, the inequality between both parties ceteris paribus increases in a recession. Thus, the split of surplus has to be adjusted. A moderate wage cut that is accompanied by an unchanged effort level allows workers and firms to (equally) share the recession's burden. Since wages, thus, go down in recession, workers-when controlling for the wage level-exert more effort in than out of recession. Since monetary incentives do not vary between treatments, no differences between treatments occur. ${ }^{13}$

Hypothesis 1 [Outcome-Based Social Preferences]: In both main treatments, BASE and CasRP, firms moderately adjust their wages downward if they are hit by a negative profit shock. This adjustment is not different between treatments.

Notably, with the standard inequity-aversion model, it cannot be rationalized as equilibrium behavior that workers share the recession's burden by increasing effort for constant wages. This is naturally true for workers that already exert the maximum effort but also holds for other workers (as is outlined in more detail in Appendix A).

When workers also care for reference points, the prediction changes: If a firm cuts wages in recession in CasRP, workers feel entitled to the wage of the initial contract. While stable wages can lead to a loss in utility due to risen inequality, wage cuts decrease workers' utility since they are perceived as reference-point violation. If workers $s u f$ ficiently care for reference points, they punish wage cuts by lowering effort to offset the reference-point violation. By how much workers have to punish wage cuts to make them unprofitable, depends on their relative reaction to stable wages. If workers reciprocate stable wages only by constant effort-as predicted by inequality aversion (see Appendix A) - their effort reduction has to overcompensate the wage cut $(|\Delta w|=10$ leads to $|\Delta e|>1)$. If stable wages are reciprocated by higher effort, a proportional effort reduction is already sufficient. In both cases, when controlling for the wage level, effort is lower for wage cuts than for stable wages. This implies that firms-with standard preferences-do not cut wages in recession. In BASE,

\footnotetext{
${ }^{13}$ Intention-based fairness models (e.g. Charness and Rabin 2002-with the reciprocity parameter $\theta$ ) potentially predict wage rigidity if one assumes that wage cuts are considered as unkind actions. The question, however, remains why a moderate wage cut should be considered unfair although a recession limits firms' abilities to pay high wages (see also Rabin 1993).
}

however, contracts are not concluded before recessions and firms cut wages. Although we may not expect such a clear-cut result, we should at least expect:

Hypothesis 2 [Contracts as Reference Points]: Wages are more rigid in CasRP than in BASE. In CasRP, a referencepoint effect is observed: controlling for the wage level, effort is lower for wage cuts than for stable (or increased) wages.

Notably, firms with standard preferences will also not lower out-of-recession wages in CasRP (compared to BASE) to preemptively mitigate the rigidity problem. The underlying idea is following: Under the parameters of the experiment, cutting wages already out-of-recession to allow for lower wages in recession leads to losses outof-recession that outweigh the gains in recession. When firms, however, are somewhat inequity-averse (see Appen$\operatorname{dix} \mathrm{A}$ ), they may have an incentive to lower wages out-ofrecession to avoid the higher inequality associated with rigid wages in recession. Notably, this potential behavioral pattern also originates from workers' resistance against wage cuts, could contribute to the overall rigidity of wages and might also be relevant in the field. As the theoretical analysis is, however, somewhat inconclusive on this point, i.e., the prediction depends on what one assumes about the firms' preferences, I do not offer a prediction here, but state an open question. Finally, following the motivation of the two control treatments, I have two conjectures.

Open question: Do firms adjust the out-of-recession wage downward in CasRP?

Conjecture 1 [Wages as reference points]: An explicit contract conclusion is necessary to generate resistance against wage cuts.

Conjecture 2 [Contracts as reference points with feedback]: Due to the better information conditions, wage cuts in CasRP-F are less pronounced than in CasRP.

\section{Results and discussion}

\subsection{Firms' Behavior-BASE vs. CasRP}

Table 3 and Fig. 1 summarize firms' behavior. Table 3 provides average wages in and out of recession as well as two measures of the wage difference in and out of recession: the (raw) wage cut and the relative wage cut. ${ }^{14}$ The later measure is provided as a complementary measure

\footnotetext{
${ }^{14}$ Due to the construction of the treatments, the term wage cut can have two different meanings: Both in BASE and in CasRP, an indirect wage cut can be observed insofar as one can compare average wages of firms in recession with average wages of firms out of recession. In CasRP, also a direct wage cut can be observed by comparing wages from stage 1 and stage 2 in case a recession occurs. Since there is no reason to expect a difference between the two measures, I report indirect wage cuts unless otherwise stated. Reporting direct wage cuts would lead to very similar results
} 
Table 3 Average wages: BASE vs. CasRP

\begin{tabular}{lllll}
\hline & Wage & Wage cut & $\begin{array}{l}\text { Relative } \\
\text { Wage cut }\end{array}$ \\
\cline { 2 - 3 } & No-recession & Recession & & 13.1 \\
\hline BASE & 60.1 & 47.0 & 6.0 & $10 \%$ \\
\hline
\end{tabular}

since firms paying high wages have much more scope to (absolutely) adjust their wages downward. Since my two hypotheses make predictions about how rigid wages are, the two wage-cut measures are the main variables to test this prediction. Notably, since $98 \%$ of all wage offers are accepted, my analysis below is based on accepted wage offers.

Wages are cut in both treatments: average wages are significantly lower in recession than out of recession. While pay is, however, cut by 13.1 points in BASE (signed-rank test: $p=0.028^{15}$ ), it is only reduced by 6.0 points (signed-rank test: $p=0.023$ ) in CasRP. This difference translates to a comparable discrepancy in the relative wage cut measure ( 21 percent vs. 10 percent). Hence, a treatment difference in line with hypothesis 2 is observed: initial contracts that potentially serve as reference points reduce wage cuts in CasRP to less than half their size in BASE. The difference between treatments is significant both for (raw) wage cuts (rank-sum test: $p=0.038$ ) and for relative wage cuts (rank-sum test: $p=0.026$ ). In addition, a difference of 7.1 points is non-negligible and economically meaningful in the sense that the predicted treatment difference would even only be 10 points when making the unrealistic assumption of completely rigid wages in the CasRP treatment (whereas workers and firms share the profit shock of 20 points equally in BASE-Appendix A).

Figure 1 shows wages over time. In support of the previous findings, firms seem to pay even more rigid wages over time in CasRP. While wages are also cut by 13.1 points in BASE in the last six rounds, they are only reduced by 1.6 points in the last third of the experiment in CasRP. Although non-parametric tests cannot confirm that wage cuts are getting smaller in CasRP (signed-rank

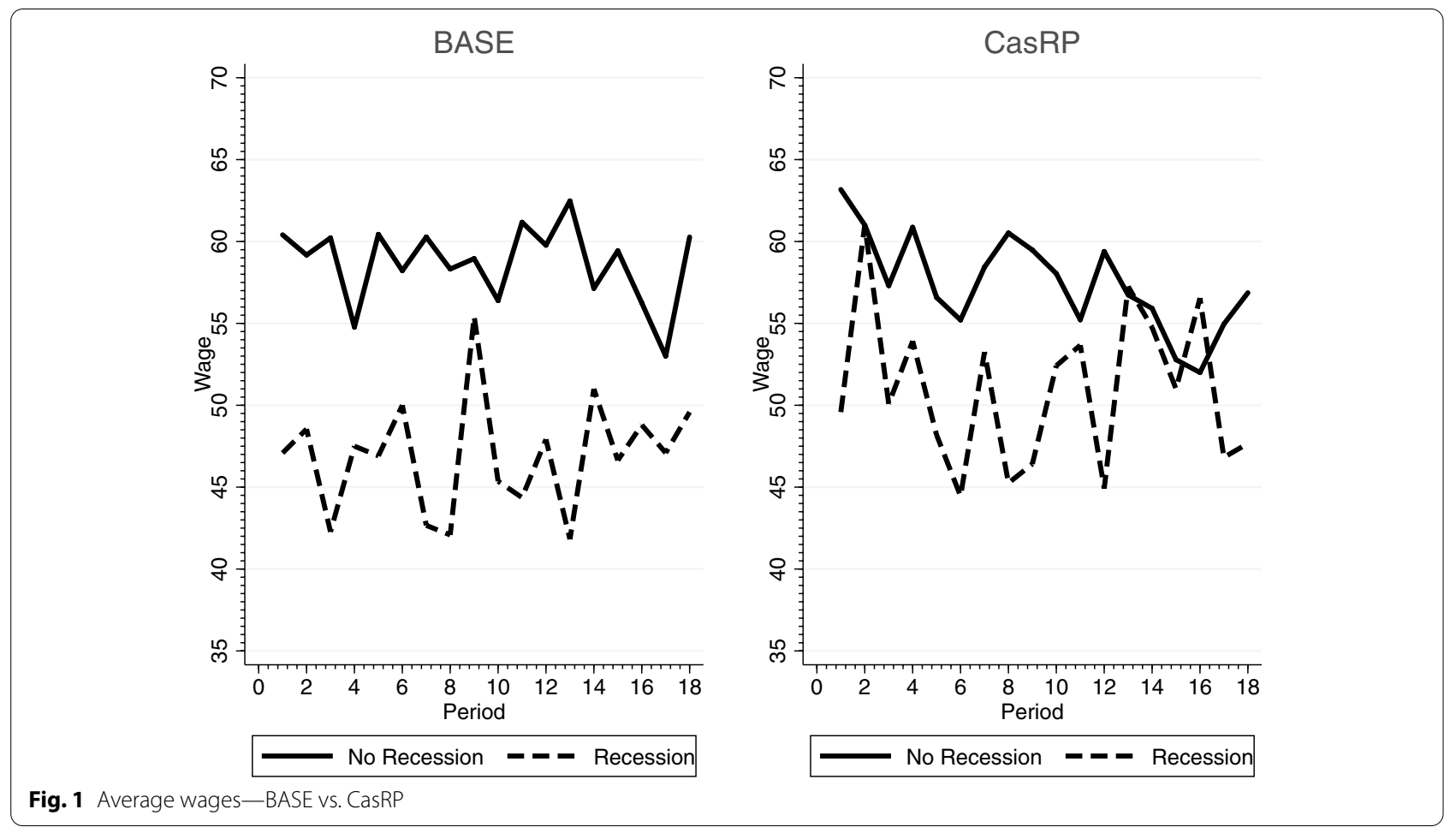

\footnotetext{
${ }_{15}$ Tests in this paper are two-sided and since my observations are strictly only independent at the session level, non-parametric tests conservatively treat one session as one independent observation. Only when reporting power results for important null results, I also use more powerful individual observations and perform one-tailed tests in case of a directed hypothesis.
} 
test, $p=0.173)$, they do show that wages actually become fully rigid in CasRP: wages are not significantly different in and out-of recession in the last rounds (signed-rank test, $p=0.345$ ). These findings clearly indicate that firms seem to learn over time to pay even more rigid wages in CasRP.

As indicated before, out-of-recession wages could vary between treatments when inequity-averse subjects who represent a firm anticipate workers' resistance against wage cuts in CasRP, potentially contributing to the overall rigidity of wages in this treatment. In line with this idea, these wages are slightly lower in CasRP (57.9) than in BASE (60.1). A non-parametric test is, however, unable to detect a significant difference (rank sum test: $p>0.20$ ) although this test is arguably underpowered. ${ }^{16}$ Potentially because of the slight initial differences, recession wages (47.0 vs. 51.9 ) are also only different with at best weak significance (rank sum test: $p=0.075$ ).

To further validate the non-parametric analysis presented so far, Table 4 shows panel random effects (RE) and fixed effects (FE) regressions with wages as the dependent variable and different specifications. All specifications control for time trends, use data from all four treatments and include a recession dummy. Interacting the recession dummy with treatment dummies in specification (2) confirms that wage cuts are significantly smaller in CasRP than in BASE. This result is robust to adding past-period information and using fixed instead of random effects (specification 3 and 4). Interestingly, in one specification, out-of-recession wages are- with marginal significance-lower in CasRP compared to BASE, indicating that some firms seem to anticipate resistance against wage cuts and try to circumvent it by lowering wages already out of recession. This result is, however, neither robust across specifications nor across the other control treatments.

Result 1 In both treatments, wages are cut in recession. Importantly, however, wages are more rigid in CasRP than in BASE (and become fully rigid at the end of the experiment). This supports hypothesis 2 . Regarding the open question, no conclusive evidence in favor of the idea

\footnotetext{
16 Power calculations based on observed standard deviations suggest that 38 (instead of 6) sessions per treatment would be needed to detect the small, observed difference in wages as statistically significant at the $5 \%$ level $80 \%$ of the time. Alternatively, one could ask with what probability a true change in behavior of 5 or 10 points would be detected (which would account either for half of or the full theoretically predicted wage reduction in BASE). Such differences would be detected as significant at the $5 \%$ level with $25 \%$ or $61 \%$ probability (or $38 \%$ or $76 \%$ using individual data). Notably, power calculations for the associated regression analysis in Table 4-based on how much the CasRP-dummy adds to the $R^{2}$-reveal a power of up to $92 \%$ even for the observed effect. Indeed, one specification finds some evidence for a small effect.
}

Table 4 Panel regressions on wages

\begin{tabular}{|c|c|c|c|c|}
\hline & (1) & (2) & (3) & (4) \\
\hline & RE & RE & RE & FE \\
\hline \multirow[t]{2}{*}{ CasRP-dummy } & 0.257 & -1.659 & $-3.285 *$ & \\
\hline & $(4.046)$ & $(4.138)$ & $(1.913)$ & \\
\hline \multirow[t]{2}{*}{ CasRP-F-dummy } & 1.388 & -0.834 & -3.347 & \\
\hline & $(3.408)$ & $(3.825)$ & $(2.104)$ & \\
\hline \multirow[t]{2}{*}{ WasRP-dummy } & 3.000 & 1.159 & -1.471 & \\
\hline & $(4.420)$ & $(4.453)$ & $(1.818)$ & \\
\hline $\begin{array}{l}\text { Recession- } \\
\text { dummy }\end{array}$ & $\begin{array}{l}-6.832 * * * \\
(1.135)\end{array}$ & $\begin{array}{l}-11.51 * * * \\
(1.550)\end{array}$ & $\begin{array}{l}-10.65 * * * \\
(2.002)\end{array}$ & $\begin{array}{l}-11.11 * * * \\
(1.759)\end{array}$ \\
\hline \multirow[t]{2}{*}{$\operatorname{Rec} \times$ CasRP } & & $5.822 * * *$ & $6.985 * * *$ & $5.879 * *$ \\
\hline & & $(2.250)$ & $(2.477)$ & $(2.413)$ \\
\hline \multirow[t]{2}{*}{ Rec $\times$ CasRP-F } & & $7.051 * *$ & $8.287 * *$ & $7.340 *$ \\
\hline & & (3.247) & (3.879) & (3.634) \\
\hline \multirow[t]{2}{*}{ Rec $\times$ WasRP } & & $5.307 * *$ & $6.073 * *$ & $5.251 * *$ \\
\hline & & $(2.153)$ & $(2.362)$ & $(2.176)$ \\
\hline \multirow[t]{2}{*}{ Wage $_{t-1}(\mathrm{No}-\mathrm{Rec})$} & & & $0.438 * * *$ & $0.0885 * * *$ \\
\hline & & & $(0.0529)$ & $(0.0289)$ \\
\hline \multirow[t]{2}{*}{ Wage $_{t-1}(\operatorname{Rec})$} & & & $0.561 * * *$ & $0.145 * * *$ \\
\hline & & & $(0.0677)$ & $(0.0383)$ \\
\hline \multirow[t]{2}{*}{ Effort $_{t-1}($ No-Rec$)$} & & & $1.723 * * *$ & $1.148 * * *$ \\
\hline & & & $(0.203)$ & $(0.147)$ \\
\hline \multirow[t]{2}{*}{ Effort $_{t-1}(\operatorname{Rec})$} & & & $0.756 *$ & $0.633 * *$ \\
\hline & & & $(0.408)$ & $(0.241)$ \\
\hline \multirow[t]{2}{*}{ First wage } & & & $0.0838 * *$ & \\
\hline & & & $(0.0271)$ & \\
\hline Period \& Period ${ }^{2}$ & $\checkmark$ & $\checkmark$ & $\checkmark$ & $\checkmark$ \\
\hline \multirow[t]{2}{*}{ Constant } & $57.83 * * *$ & $59.46 * * *$ & $23.98 * * *$ & $49.13 * * *$ \\
\hline & $(3.280)$ & $(3.343)$ & $(3.854)$ & $(2.274)$ \\
\hline Observations & 2858 & 2858 & 2696 & 2696 \\
\hline$R^{2}$ & 0.0329 & 0.0384 & 0.0984 & 0.120 \\
\hline
\end{tabular}

Notes: Panel random effects (RE) and fixed effects (FE) regressions on wages for all treatments. Standard errors are reported in parentheses, adjusted for clustering at the session level since observations may be dependent within session. $* * *$ indicates significance at the 1 percent level, $* *$ at the 5 percent level, and $*$ at the 10 percent level

that rigid wages are due to out-of-recession wage adjustments in CasRP is found.

\subsection{Workers' Behavior-BASE vs. CasRP}

Is there a reference-point effect present in CasRP that could explain why wages are more rigid in this treatment? Table 5 provides a first average measure of workers' behavior in the two different treatments. In both treatments, average effort seems to be cut. While this reduction is, however, significant in BASE (signed-rank test: $p$ $=0.028$ ), this is not true for CasRP (signed-rank test: $p$ 
Table 5 Average effort: BASE vs. CasRP

\begin{tabular}{llll}
\hline & \multicolumn{2}{l}{ Effort } & Effort cut \\
\cline { 2 - 3 } & No-Recession & Recession & \\
\hline BASE & 4.0 & 3.3 & $\mathbf{0 . 7}$ \\
CasRP & 4.1 & 3.8 & $\mathbf{0 . 3}$ \\
\hline
\end{tabular}

$=0.248)$. Of course, workers' effort choices can only be fully understood when analyzing them accounting for their dependence on wages.

Figure 2 gives a first impression why a treatment difference in wage-setting behavior might be observed. This figure reports workers' reaction, their effort change, to different wage changes of firms for CasRP, for which direct wage-cut data is available (see footnote 14). While wages are cut roughly half of the time and remain exactly constant in one-third of the cases, firms somewhat surprisingly also increase the recession wage sometimes. A potential rationale is that increasing the wage in a recession may be perceived as a particular strong gift that may not even be that costly, at least for the more frequent moderate wage increases. Indeed, the graph shows a punishment-reward pattern of workers' behavior: workers punish wage cuts by decreasing effort, and they reward stable or increased wages by increasing effort (both in absolute terms). Notably, as discussed before, lower (higher) wages are generally reciprocated with lower (higher) effort in gift-exchange games, completely independent of wage cuts. This positive wageeffort relationship could in principle explain the observed pattern. To fully understand the implications of workers' behavior one has to analyze workers' reactions to wage cuts accounting for this relationship.

To provide such an analysis, Table 6 reports fixed effects regressions for CasRP that explain effort and control for the wage level (as well as a quadratic wage term and a quadratic time trend). ${ }^{17}$ While specification (2) adds a simple recession dummy, specification (3) adds a dummy, Rec $\times$ Wage cut, that only has value one if a recession occurs and the firm cuts wages. Finally, specification (4) provides an alternative way to control for the wage level, namely by including 14 wage-dummies for wage intervals with length of $5([30,35],(35,40], \ldots,(95,100])$.

\footnotetext{
17 To control for the fact that effort is discrete, $e \in\{1,10\}$, I also run random-effects ordered probit and ordered legit regressions. Moreover, instead of wages one could also use the wage-effort ratio as the dependent variable. Standard errors are clustered at the session level (as the level of independent observations) because observations within session may heavily depend on each other. To control for the dependence of observations both at the session and the individual level, I also run hierarchical linear regressions with random intercepts on subjects nested in sessions. All these regressions lead to very similar results.
}

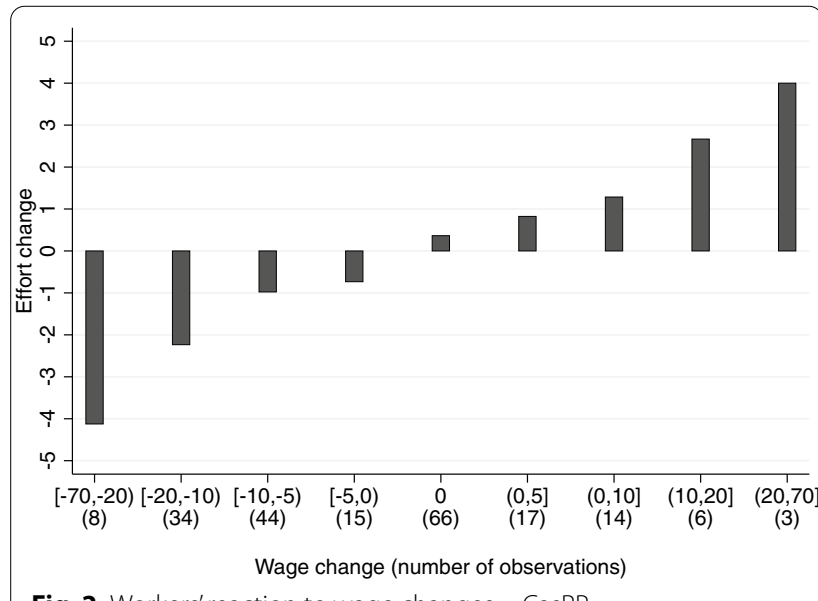

Fig. 2 Workers' reaction to wage changes-CasRP

Table 6 supports the notion of a punishment reward pattern, at least in relative terms: Unpredicted by my model of inequality aversion, stable or increased wages are-controlling for the wage level-reciprocated with significantly higher effort $(0.41)$ in recession. If pay is instead cut, average effort is 0.26 points lower and the resulting effort is statistically not different from zero (F-test: $p=0.324$ ). Put differently, since stable (or increased) wages are already rewarded, workers do not have to overcompensate the initial wage decrease to render wage cuts unprofitable. Even a less severe reaction leads to the predicted reference-point effect: controlling for the wage level, effort is lower for wage cuts than for stable wages, providing an incentive not to cut wages.

Does the observed reference-point effect lead to behavioral differences across treatments? Table 7 provides an extended regression analysis for all treatments. While specification (2) disentangles the recession dummy by adding treatment-specific recession dummies, specification (3) implements separate dummies for wage cuts and stable (or increased) wages for all treatments with reference points (CasRP, WasRP, CasRP-F). In these treatments, this separation is meaningful since wage cuts can be perceived as reference-point violations. Finally, specification (4), (5) and (6) look at further controls and fixed effects specifications.

Specification (3) shows that the reference-point effect observed before leads to meaningful treatment differences: When controlling for the wage level, average effort in recession increases by 0.63 points in BASE, reflecting that workers share (an unequal) part of the recession's burden even though wages are on average adjusted downwards. This increase does not change significantly for stable (or increased) wages in CasRP. It is, however, significantly lower for wage cuts ( 0.55 points). 
Table 6 Panel regressions on effort - CasRP

\begin{tabular}{lllll}
\hline & $\mathbf{( 1 )}$ & $\mathbf{( 2 )}$ & $\mathbf{( 3 )}$ & $\mathbf{( 4 )}$ \\
& $\mathrm{FE}$ & $\mathrm{FE}$ & $\mathrm{FE}$ & $\mathrm{FE}$ \\
\hline Wage & $0.110 * *$ & $0.113 * *$ & $0.113 * *$ & \\
& $(0.0316)$ & $(0.0308)$ & $(0.0315)$ & \\
Recession-dummy & & $0.285 *$ & $0.408 * *$ & $0.379 *$ \\
& & $(0.132)$ & $(0.150)$ & $(0.150)$ \\
Rec Wage cut & & & $-0.257 * *$ & $-0.176 * *$ \\
& & & $(0.0852)$ & $(0.0648)$ \\
Wage ${ }^{2}$ & $\checkmark$ & $\checkmark$ & $\checkmark$ & \\
Wage-dummies & & & & $\checkmark$ \\
Period \& Period ${ }^{2}$ & $\checkmark$ & $\checkmark$ & $\checkmark$ & $\checkmark$ \\
Constant & $-2.601 * *$ & $-2.779 * *$ & $-2.764 * *$ & $8.301 * * *$ \\
& $(0.892)$ & $(0.837)$ & $(0.846)$ & $(0.696)$ \\
Observations $^{2}$ & 827 & 827 & 827 & 827 \\
R $^{2}$ & 0.669 & 0.672 & 0.672 & 0.683
\end{tabular}

Notes: Panel fixed effects (FE) regressions on effort, only for the CasRP treatment. Standard errors are reported in parentheses, adjusted for clustering at the session level since observations may be dependent within session. $* * *$ indicates significance at the 1 percent level, $* *$ at the 5 percent level, and $*$ at the 10 percent level

The implication of this observation is that workers seem less willing to accept wage cuts-reference-point violations-in CasRP compared to BASE: they do not share the recession's burden as much in this treatment as they do in BASE where wages are on average substantially cut but this cut cannot be perceived as a reference-point violation. While workers in BASE provide firms with an extra of 6.3 points (controlling for the wage level), they only provide 0.8 points for wage cuts in CasRP. In other words, the observed reference-point effect in CasRP implies that wage cuts in CasRP are punished compared to average behavior in BASE. This provides an explanation for the treatment difference in firms' behavior.

Result 2 In line with hypothesis 2, workers in CasRP have established a reference point: controlling for the wage level, effort is lower for wage cuts than for stable (or increased) wages. This effect leads to a significant treatment difference that explains why wages are more rigid in CasRP: compared to BASE, wage cuts are punished.

A concern could be that average differences between wage cuts and stable wages are fairly small in CasRP (0.18-0.26 effort units). Reassuringly, although by far not always significant, profit differences for firms are in line with the idea that firms that pay stable (or increased) wages earn more in CasRP (see Additional file 1: Appendix $C$ ). In addition and as discussed below, the difference between wage cuts and stable wages also seems to be more pronounced in WasRP with a similar overall effect on wages. The appendix also shows that workers seemif anything-to earn slightly more in recession in treatments with reference points, increasing the inequality between firms and workers and, hence, suggesting that workers behave less fair-minded.

\subsection{Control treatments}

Is an explicit conclusion of a contract between firms and workers necessary to create resistance against wage cuts? Does more information lead to more rigid wages? Table 8 shows average wages and the two wage cut measures for all treatments. Even without an explicit contract conclusion (WasRP), wage cuts of similar magnitude are observed than the one in CasRP. ${ }^{18}$ This finding is also supported by the regression analysis of Table 4 . It shows that in WasRP wages are adjusted downward but to significantly lesser extent than in BASE, as in CasRP. Moreover, Additional file 1: Appendix B provides a more detailed analysis along the lines of the two main treatments. The upshot is that a similar-if anything intensified-reference-point effect is observed: workers (relatively) punish wage cuts.

Table 8 also shows that the average wage cut in CasRP-F is roughly of the same size as in CasRP. ${ }^{19}$ Table 4 corroborates this finding. Hence, at least on average, additional feedback for firms seems not to alter the results and does not lead to completely rigid wages. Notably, the average results, however, mask non-negligible differences between CasRP and CasRP-F. Firms are slightly more likely to pay stable (or increased) wages in CasRP-F (CasRP-F: $60.3 \%$ vs. CasRP: $51.2 \%$ $\mathrm{Z}=1.84, p=0.065$ ), as predicted by conjecture 2 . This effect, however, appears to be negated by an increase in the very strong wage cuts above 20 points (CasRP-F: $6.5 \%$ vs. CasRP: $2.9 \%-\mathrm{Z}=1.73, p=0.083$ ). Additional file 1: Appendix B further illuminates these findings by showing that not only firms but also workers change their behavior in response to the change in information: workers in CasRP-F do not (significantly) punish wage cuts compared to stable (or increased) wages such that there is no reference-point effect. Overall, changes both in workers' and firms' behavior imply that there is no average effect.

Result 3 In contrast to conjecture 2, more information does on average not lead to more rigid wages. In

\footnotetext{
${ }^{18}$ CasRP vs. WasRP - (raw) wage cut: $p=0.424$; relative wage cut: $p=0.424$; Base vs. WasRP - (raw) wage cut: $p=0.006$; relative wage cut: $p=0.006$. $p$-values based on rank-sum tests.

${ }^{19}$ CasRP vs. CasRP-F - (raw) wage cut: $p=0.424$, relative wage cut: $p=$ 0.212; Base vs. CasRP-F - (raw) wage cut: $p=0.054$, relative wage cut: $p=$ 0.008 . $p$-values based on rank-sum tests.
} 
Table 7 Panel Regressions on effort

\begin{tabular}{|c|c|c|c|c|c|c|}
\hline & (1) & (2) & (3) & (4) & (5) & (6) \\
\hline & & & & & & \\
\hline Wage & $\begin{array}{l}0.132 * * * \\
(0.0183)\end{array}$ & $\begin{array}{l}0.132 * * * \\
(0.0184)\end{array}$ & $\begin{array}{l}0.132 * * * \\
(0.0185)\end{array}$ & $\begin{array}{l}0.162 * * * \\
(0.0341)\end{array}$ & $\begin{array}{l}0.131 * * * \\
(0.0186)\end{array}$ & $\begin{array}{l}0.161 * * * \\
(0.0336)\end{array}$ \\
\hline CasRP-dummy & $\begin{array}{l}0.219 \\
(0.281)\end{array}$ & $\begin{array}{l}0.345 \\
(0.264)\end{array}$ & $\begin{array}{l}0.343 \\
(0.265)\end{array}$ & $\begin{array}{l}1.217 \\
(1.143)\end{array}$ & & \\
\hline CasRP-F-dummy & $\begin{array}{l}0.0701 \\
(0.331)\end{array}$ & $\begin{array}{l}0.257 \\
(0.306)\end{array}$ & $\begin{array}{l}0.255 \\
(0.307)\end{array}$ & $\begin{array}{l}0.530 \\
(0.973)\end{array}$ & & \\
\hline WasRP-dummy & $\begin{array}{l}0.0460 \\
(0.333)\end{array}$ & $\begin{array}{l}0.0948 \\
(0.331)\end{array}$ & $\begin{array}{l}0.0950 \\
(0.333)\end{array}$ & $\begin{array}{l}1.242 \\
(1.032)\end{array}$ & & \\
\hline Recession-dummy & $\begin{array}{l}0.334 * * * \\
(0.0905)\end{array}$ & $\begin{array}{l}0.640 * * * \\
(0.128)\end{array}$ & $\begin{array}{l}0.630 * * * \\
(0.128)\end{array}$ & $\begin{array}{l}0.556 * * * \\
(0.170)\end{array}$ & $\begin{array}{l}0.624 * * * \\
(0.122)\end{array}$ & $\begin{array}{l}0.548 * * * \\
(0.165)\end{array}$ \\
\hline $\operatorname{Rec} \times$ CasRP & & $\begin{array}{l}-0.386 * * * \\
(0.143)\end{array}$ & & & & \\
\hline Rec $\times$ CasRP-F & & $\begin{array}{l}-0.637 * * * \\
(0.195)\end{array}$ & & & & \\
\hline Rec $\times$ WasRP & & $\begin{array}{l}-0.137 \\
(0.184)\end{array}$ & & & & \\
\hline Rec $\times$ CasRP $\times$ Wage cut & & & $\begin{array}{l}-0.548 * * * \\
(0.141)\end{array}$ & $\begin{array}{l}-0.407 * \\
(0.213)\end{array}$ & $\begin{array}{l}-0.547 * * * \\
(0.137)\end{array}$ & $\begin{array}{l}-0.402 * \\
(0.209)\end{array}$ \\
\hline $\operatorname{Rec} \times$ CasRP $\times$ No wage cut & & & $\begin{array}{l}-0.222 \\
(0.172)\end{array}$ & $\begin{array}{l}-0.148 \\
(0.223)\end{array}$ & $\begin{array}{l}-0.214 \\
(0.168)\end{array}$ & $\begin{array}{l}-0.137 \\
(0.219)\end{array}$ \\
\hline Rec $\times$ CasRP-F $\times$ Wage cut & & & $\begin{array}{l}-0.798 * * * \\
(0.167)\end{array}$ & $\begin{array}{l}-0.623 * * * \\
(0.241)\end{array}$ & $\begin{array}{l}-0.789 * * * \\
(0.163)\end{array}$ & $\begin{array}{l}-0.606 * * \\
(0.236)\end{array}$ \\
\hline Rec $\times$ CasRP-F $\times$ No Wage cut & & & $\begin{array}{l}-0.519 * * \\
(0.253)\end{array}$ & $\begin{array}{l}-0.468 \\
(0.285)\end{array}$ & $\begin{array}{l}-0.527 * * \\
(0.251)\end{array}$ & $\begin{array}{l}-0.472 \\
(0.281)\end{array}$ \\
\hline Rec $\times$ WasRP $\times$ Wage cut & & & $\begin{array}{l}-0.378 * * \\
(0.156)\end{array}$ & $\begin{array}{l}-0.401 * \\
(0.210)\end{array}$ & $\begin{array}{l}-0.379 * * \\
(0.154)\end{array}$ & $\begin{array}{l}-0.404 * \\
(0.211)\end{array}$ \\
\hline Rec $\times$ WasRP $\times$ No Wage cut & & & $\begin{array}{l}0.106 \\
(0.212)\end{array}$ & $\begin{array}{l}0.177 \\
(0.242)\end{array}$ & $\begin{array}{l}0.111 \\
(0.209)\end{array}$ & $\begin{array}{l}0.184 \\
(0.240)\end{array}$ \\
\hline Wage $^{2}$ & $\checkmark$ & $\checkmark$ & $\checkmark$ & $\checkmark$ & $\checkmark$ & $\checkmark$ \\
\hline Wage ${ }^{*}$ CasRP \& Wage ${ }^{2 *}$ CasRP & & & & $\checkmark$ & & $\checkmark$ \\
\hline Wage ${ }^{*}$ CasRP- $F \&$ Wage ${ }^{2 *}$ CasRP-F & & & & $\checkmark$ & & $\checkmark$ \\
\hline Wage*WasRP \& Wage ${ }^{2 *}$ WasRP & & & & $\checkmark$ & & $\checkmark$ \\
\hline Period \& Period ${ }^{2}$ & $\checkmark$ & $\checkmark$ & $\checkmark$ & $\checkmark$ & $\checkmark$ & $\checkmark$ \\
\hline Constant & $\begin{array}{l}-3.004 * * * \\
(0.503)\end{array}$ & $\begin{array}{l}-3.128 * * * \\
(0.495)\end{array}$ & $\begin{array}{l}-3.082 * * * \\
(0.494)\end{array}$ & $\begin{array}{l}-3.626 * * * \\
(0.863)\end{array}$ & $\begin{array}{l}-2.856 * * * \\
(0.499)\end{array}$ & $\begin{array}{l}-2.816 * * * \\
(0.401)\end{array}$ \\
\hline Observations & 2858 & 2858 & 2858 & 2858 & 2858 & 2858 \\
\hline$R^{2}$ & 0.517 & 0.518 & 0.519 & 0.520 & 0.622 & 0.627 \\
\hline
\end{tabular}

Notes: Panel random effects (RE) and fixed effects (FE) regressions on effort for all treatments. Standard errors are reported in parentheses, adjusted for clustering at the session level since observations may be dependent within session. $* * *$ indicates significance at the 1 percent level, $* *$ at the 5 percent level, and $*$ at the 10 percent level

addition, in contrast to conjecture 1, an explicit violation of an agreed upon contract is surprisingly not necessary to generate resistance against wage cuts.

Overall, this study's findings are in line with idea that reference points motivate resistance against wage cuts even though there is no violation of an explicit agreement. Contracts seem to serve as reference points not because of the explicit agreement but simply because they determine the out-of-recession wage and convey this information to the worker, which is sufficient to create feelings of entitlement. Notably, while it is conceivable that initial contracts in CasRP influence subjects expectations in a way not feasible in BASE, no such initial contracts exist in WasRP. The result is, however, in line with findings that entitlements could constitute a "moral 
Table 8 Average wages: BASE vs. CasRP/ WasRP/ CasRP-F

\begin{tabular}{lllll}
\hline & Wage & Wage cut & $\begin{array}{l}\text { Relative } \\
\text { Wage cut }\end{array}$ \\
\cline { 2 - 3 } & No-Recession & Recession & & Was \\
\hline BASE & 60.1 & 47.0 & 13.1 & 0.21 \\
CasRP & 57.9 & 51.9 & 6.0 & 0.10 \\
WasRP & 60.4 & 53.8 & 6.6 & 0.11 \\
CasRP-F & 58.8 & 53.4 & 5.4 & 0.09 \\
\hline
\end{tabular}

property right" that is independent of players' legal property rights (GÄchter and Riedl 2005; Bolton and Karagözoglu 2015).

On a more general level, I cannot rule out that other motivational forces, apart from reference points, might contribute to the observed results. Findings are for example consistent with the idea of an anchoring effect (see Furnham and Boo 2011 for a recent review). Even though the out-of-recession wage has no relevance in WasRP in case a recession occurs, it still influences the outcome. Relatedly, since workers seem to earn slightly more in recession when reference points are present, self-serving biases (Babcock and Loewenstein 1997) could also be a driving force. Of course, these different motivations may not be mutually exclusive: Self-serving biases may simply reinforce reference points.

\section{Conclusion}

In this paper, I examine whether reference points affect workers' perception of a "fair" recession wage and, thus, cause wage rigidity. In a controlled experimental laboratory market, I manipulate whether workers' fairness perceptions can be shaped by initially concluded contracts and the wage they stipulate. I find that wages are considerable more rigid with these initial contracts than without. When initial out-of-recession wages can serve as a reference point, workers punish wage cuts relative to stable wages, providing a reason for firms' wage-setting behavior. Interestingly, workers still reward stable wages. Thus, rigid wages are observed despite the fact that a recession provides a good reason to adjust the wage level. Unexpectedly, they even emerge when workers have not agreed to an initial contract and, thus, arguably have no "objective" justification to feel entitled to their reference wage. This highlights the strength of reference points in my setting.

What do my findings imply about reference points and wage rigidity outside the lab? Do reference points provide one explanation for wage rigidity in the field? Like with all empirical studies, such statements should be made with great care. My results are obtained in a specific environment, one that-in order to isolate one plausible explanation of wage rigidity-abstracts from many aspects of field labor markets, e.g. workers cannot be fired and firms have only one worker. Having said this, reference points are surprisingly strong in my setting. Unlike in other studies, a good reason-the recession-does not mitigate their effect. A key feature of my design is that existing contractual arrangements have to be revised, providing initial wages with a realistic shot at serving as reference points. In contrast, wage cuts e.g. in Chen and Horton (2014) and Bracha et al. (2015) were implemented by a new contract offer that simply stipulated a lower wage, not by a revision of an existing contract. Moreover, it seems likely that reference points also play a crucial role in the field since important real-world features that reinforce them are even missing in my setting: workers in the field "associate pay with self-worth" and also punish wage cuts because they want to maintain their standard of living (Bewley 1999, p.432).

One abstraction of my design is to deliberately disregard the role of reputational concerns by implementing stranger matching. As outlined before, this is done to allow for a clean identification of the effects of the particular reference point under investigation. Moreover, implementing partner matching in my setting would capture that field labor relationships are not one-shot but also seems to emphasize reputational concerns too strongly. Experimental rounds are very short-thereby making future periods very salient-compared to field labor-market contract periods. Workers' resistance against wage cuts in the field seems likely to be driven by emotions triggered by cuts when the importance of future contract periods is fairly inconspicuous due to the longer time horizon. Stranger matching seems to reflect this to a better extent than partner matching. For this reason, I leave it for future research to analyze the interaction of reputational concerns and wage rigidity. ${ }^{20}$

Another open question is the effect of booms. One the one hand, one could argue that if workers believe that firms mostly benefit from booms, this may create an additional mechanism for rigid wages because workers might then perceive recessions as entrepreneurial risk and, thus, not be willing to share the recession's burden. This would be completely independent of whether initial contracts have been concluded or not. One the other hand, if workers' fairness perceptions are really driven by self-serving biases, the rationale of the former statement is not so clear. Workers might-contrarily to what we observe for bustsnot perceive initially concluded contracts as a constraint and demand their share of the boom's surplus, e.g. in form of bonuses or other flexible pay components. Whatever

\footnotetext{
${ }^{20}$ A real-effort experiment with partner matching in which providing effort takes some time-making future period less salient-could capture reputational concerns, emotional reactions, and their interactions with reference points more adequately. Naturally, this kind of setting is more complex and does not allow for as much repetition and learning as my simpler setting does.
} 
the answers to those questions may be, this paper shows that reference points alone already provide an explanation for more rigid wages in recession in a controlled laboratory environment, independent of other explanations that may or may not reinforce this phenomenon.

\section{Supplementary Information}

The online version contains supplementary material available at https://doi. org/10.1186/s12651-021-00284-2.

Additional file 1. Online Appendix.

Additional file 2. "Readme" file for dataset.

Additional file 3. Dataset.

\section{Acknowledgements}

For helpful suggestions, I would like to thank Andreas Bernecker, Dirk Engelmann, Urs Fischbacher, Leonie Gerhards, Botond Köszegi, Nikos Nikiforakis, Jörg Oechsler, Henrik Orzen, Alexander Paul, Stefan Penczynski, Clemens Puppe, Klaus Schmidt, and Sigrid Suetens. I also received helpful comments from participants at seminars in Abu Dhabi, Hamburg, Heidelberg, Mannheim, Munich, the Thurgau Experimental Economics Meeting 2013 (Theem), the Florence Workshop on Experimental and Behavioral Economics 2013, the ESA World Meeting 2013 (Zurich), the 8th Nordic Conference on Behavioral and Experimental Economics 2013 (Stockholm), the Gesellschaft für experimentelle Wirtschaftsforschung 2013 (Helmstedt), the EEA annual meeting 2014 (Toulouse).

\section{Authors' contributions}

Not applicable. No research assistants were used.

\section{Funding}

Funding from the DGF is gratefully acknowledged.

\section{Avaiability of data and materials}

The dataset used during the current study is available as Additional files 2 and 3.

\section{Ethics approval and consent to participate}

No IRB approval was obtained as the University of Mannheim did not have IRBs at the time the study was implemented. For this reason (and since the study involved only minimal risk), solely the approval of the director of mLab at the University of Mannheim (at which the experiment was run) was obtained. In order to participate in the experiment, subjects had to register in advance for the mLab database. During this registration process a general consent to participate was obtained.

\section{Consent for publication}

Not applicable. The study does not include details, images, or videos relating to an individual person. Thus, no consent for publication was obtained.

\section{Competing interests}

The authors declare that they have no competing interests.

\section{Appendix A Theory and hypotheses} Hypothesis 1

I formalize the first hypothesis using preferences of inequity-aversion as introduced by Fehr and Schmidt (1999) (henceforth FS). ${ }^{21}$ I assume that workers have FS-preferences, whereas firms have standard preferences.

\footnotetext{
${ }^{21}$ Importantly, the derived predictions are not specific to inequity-aversion. Social welfare preferences (Charness and Rabin 2002) would lead to qualitatively similar results.
}

$$
\begin{array}{r}
U_{W}\left(x_{W}, x_{F}\right)=x_{W}-\alpha \cdot \max \left[x_{F}-x_{W}, 0\right] \\
-\beta \cdot \max \left[x_{W}-x_{F}, 0\right]
\end{array}
$$

where $x_{W}$ and $x_{F}$ are the monetary payoff of the worker $(\mathrm{W})$ and the firm (F) and $\alpha(\beta)$ reflects how much workers suffer from disadvantageous (advantageous) inequality. FS assume that $\beta \leq \alpha$ and that $0 \leq \beta<1$.

Crucially, if workers are sufficiently inequity-averse or fair-minded $\left(\beta>\frac{18}{74} \approx 0.243 ; \alpha>\frac{11}{2} \beta-\frac{3}{2}\right)$, firms offer a high wage and workers reciprocate by a high effort $(w=84, e=10)$. In recession, the negative profit shock is equally split $\left(w_{R e c}=74, e_{R e c}=10\right)$. More precisely: Out-ofrecession, firms offer the highest possible wage that equalizes payoffs and to which workers can react with the highest possible effort $\left(w=84, e=10, x_{W}=x_{F}=66\right)$. Workers reciprocate the high wage with the highest effort level if they are sufficiently averse against advantageous inequality, in this case $\beta>\frac{3}{13} \approx 0.230$. Providing one unit less effort will save the worker (at most) 3 points but advantageous inequality will rise from 0 to 13 points. Additionally, workers have to be sufficiently averse against disadvantageous inequality $\left(\alpha>\frac{11}{2} \beta-\frac{3}{2}\right){ }^{22}$ This ensures that firms do not have an incentive to pay less than the payoff-equalizing wage, $w=84$. In recession, firms again offer the highest wage that equalizes payoffs (accounting for the negative profit shock) and to which workers respond with the highest possible effort $\left(w^{R e c}=74, e^{R e c}=10, x_{W}^{R e c}=x_{F}^{R e c}=56\right)$. Note however, that in recession workers have to be slightly more fair-minded, $\beta>\frac{18}{74} \approx 0.243$ : Firms cannot make losses in my setting which restricts the degree of advantageous inequality. Receiving a wage of 74 and providing $e=1$ instead of $e=10$ saves the worker 18 points and increases advantageous inequality only by 74 points.

In a similar fashion as before, one can show that if workers are only fair-minded to a very low degree $\left(\beta<\frac{1}{11} \approx 0.090\right)$, workers exert minimal effort $(e=1)$. The underlying idea is that workers can always save (at least) 1 point by lowering effort by one unit which would increase advantageous inequality by 11 points. Firms should anticipate workers' behavior and only offer the minimum wage $(w=30)$, both in and out of recession. If workers are fair-minded to an intermediate degree $\left(\frac{1}{11} \leq \beta \leq \frac{18}{74}\right)$, intermediate equilibria arise in which intermediate wage offers are reciprocated by

\footnotetext{
${ }^{22}$ The condition for $\alpha$ arises from the comparison of the two situations $U_{W}(W=83, e=10)=65-2 \alpha<68-11 \beta=U_{W}(W=83, e=9)$. If the condition is not met, an equilibrium with a slightly lower wage, e.g. $w=83$ or $\mathrm{w}=82$, arises in case firms have standard preferences. In case firms are also (sufficiently) inequity averse, the outlined equilibrium persist, because firms avoid inequality.
} 
intermediate effort levels (see example below). In recession, wages are cut by (at least) 10 points.

Notably, the adjustment of the split of surplus cannot be done through increased effort and constant wages, at least not in equilibrium. Sufficiently fair-minded workers already exert the maximum effort. But the statement is even true for less fair-minded workers. This is trivial for workers that are only fair-minded to a very limited degree because they will always provide minimal effort in and out-of-recession, as argued above. For workers with intermediate degrees of fairness, rational firms in equilibrium already choose their out-of-recession wage such that it induces the highest effort level that is possible when taking the limited degree of the worker's fairness into account. With constant wages, the recession increases the level of inequality. But since the utility function is linear in inequity aversion, one unit more effort is still associated with the same costs and benefits (of reduced inequality) as out of recession.

As an example, consider the case that workers are sufficiently inequity averse such that saving 2 points and increasing inequality by 12 points is not attractive to them $\left(\beta \geq \frac{2}{12}\right)$ but saving three points and increasing inequality by 13 points is $\left(\beta<\frac{3}{13}\right)$. Due to the increasing cost function, this implies that firms cannot induce an effort of 9 or 10 but only 8. Thus, out-of-recession, firms will pay $w=71$ to induce workers to exert an effort of $e=8$, equalizing payoffs at $x_{W}=x_{F}=59$. Keeping this wage (as well as the effort) constant in recession, will increase inequality considerably $\left(x_{W}^{R e c}=59, x_{F}^{R e c}=39\right)$. But the cost of reducing this inequality stays the same as out of recession: Increasing effort beyond 8 to 9 still has a cost 3 and a benefit in reduced inequality of 13, which a worker with an intermediate aversion to inequality is not willing to take. Anticipating this outcome, the firm will reduce the wage to $w^{\text {Red }}=61$ such that payoffs can be equalized. Finally, it is noteworthy that constant wages and increased effort are not an equilibrium phenomenon, but sufficiently inequality averse player may well increase effort for constant wages in recession off-equilibrium. ${ }^{23}$

To accommodate that laboratory subjects are fairminded to different degrees, the literature often considers two-type models (see Kocher and Strasser 2011 and FS). Firms in my setting could e.g. assume that a fraction $\mu$ of workers is sufficiently fair-minded $\left(\beta>\frac{18}{74}\right)$, whereas $1-\mu$ is (quasi-)selfish $\left(\beta<\frac{1}{11}\right)$. The intuition of these kind of models is quite clear: It is rational both for selfish and fair-minded firms to propose a high wage $(w=84)$ if

\footnotetext{
${ }^{23}$ A sufficiently inequity-averse worker will reciprocate a wage of 71 with 8 out of recession but provide an effort of 10 in recession (both to equalize payoffs). Notably, this cannot be an equilibrium outcome as the firm will benefit from deviating and paying the worker a higher wage out-of-recession.
}

the fraction of fair-minded workers is high enough: In my case, $\mu>0.46 .^{24}$

Overall it holds that if workers are sufficiently fairminded, the negative profit-shock is equally shared between workers and firms by a moderate wage cut of 10 points. Naturally, one might not expect such a clearcut result, but controlling for the wage level, workers should at least provide more effort in recession than out of recession.

\section{Hypothesis 2}

I extend the model of FS (by a fourth term) to incorporate that workers behavior might be reference-dependent with respect to the previous out-of-recession wage. This extension is inspired by the general idea of Hart and Moore (2008) (henceforth HM) that contracts serve as reference point because they create feelings of entitlement. Although HM do not explicitly deal with renegotiations, the implication of their analysis is that wages should be more rigid in recession with initial contracts than without. In situations without initial contracts (BASE), I assume that FS-preferences govern the relationship between workers and firms.

In the CasRP treatment, contracts can serve as reference points and workers' preferences as described in equation (3) can be modified:

$$
\begin{aligned}
U_{W}\left(x_{W}, x_{F}\right)= & x_{W}-\alpha \cdot \max \left[x_{F}-x_{W}, 0\right]-\beta \cdot \max \left[x_{W}-x_{F}, 0\right] \\
& -\gamma \cdot I_{\left[w_{2}<w_{1}\right]} \max \left[\theta \cdot\left(w_{1}-w_{2}\right)-10 \cdot\left(e_{1}-e_{2}\right), 0\right]
\end{aligned}
$$

The basic idea of the fourth term is the following: The weighted difference between the reference-point wage out of recession and the actual wage in recession, $\theta \cdot\left(w_{1}-w_{2}\right)$ can be interpreted as the worker's aggrievement caused by getting less than what you are entitled to and $\theta$ represents a weighting parameter. Workers can offset their aggrievement, $\theta \cdot\left(w_{1}-w_{2}\right)$, by adjusting their effort downward and hence punishing the firm by $10 \cdot\left(e_{1}-e_{2}\right)$.

Notably, as outlined before for hypothesis 1, stable wages cannot be reciprocated with higher effort levels in recession since the highest (feasible) effort level has already been induced out of recession. This may be all the more true since my approach-following HMonly models a negative impact of a reference-point violation but not a positive effect when a reference point is met. Thus, to establish that firms lose more by

\footnotetext{
${ }^{24} \mu \cdot U_{W}(w=84, e=10)+(1-\mu) \cdot U_{W}(w=84, e=1)>U_{W}(w=30, e=1)$ $\Leftrightarrow \mu 66+(1-\mu) 0>30$. In recession, this fraction is even lower: $\mu \cdot U_{W}(W=74$ $(W=74, e=10)+(1-\mu) \cdot U_{W}(W=74, e=1)>\mu \cdot U_{W}(W=30, e=3)+(1-\mu)$ $\cdot U_{W}(W=30, e=1) \Leftrightarrow \mu 56+(1-\mu) 0>\mu 20+10$.
} 
reduced effort than they gain by paying lower wages, workers have to overcompensate the wage decrease by a relatively larger effort decrease. In other words, one has to assume that $\theta>1$, deviating from HM.

Whether workers, however, really want to offset their aggrievement depends on the weighting parameter $\gamma$ : Only when workers weigh the negative impact of a reference-point violation high enough $(\gamma>10)$, they punish wage cuts by lowering effort although this also leads to higher inequality associated with lower utility. More precisely: Assume that firms and workers act according to the FS-considerations of hypothesis $1\left(w=84, e=10, x_{W}=x_{F}=66\right)$ and that workers are sufficiently fair-minded $\left(\beta>\frac{18}{74} \approx 0.243\right)$. Consider the case that firms cut wages in recession by one unit, $w^{R e c}=83$. If $\gamma>10$, then even the smallest wage reduction will lead to a loss of utility of more than 10. This is due to the reference-point violation. Reducing effort by one unit will, however, offset this negative effect and will lead to a utility loss that is strictly smaller than 10 . A one-point decrease of effort increases advantageous inequality by 13 points but workers still saves 3 points of cost of effort. Hence, if workers weight the negative impact of violating their reference point to a sufficient degree, firms with standard preferences will not cut wages $\left(w^{R e c}=84, e^{R e c}=10, x_{F}^{R e c}=46, x_{W}^{R e c}=66\right)$. This is due to the fact that a wage reduction is always followed by a sufficiently large reduction of effort that implies a net reduction in firms' payoffs $(\theta>1)$.

If subjects do not care at all about reference points $(\gamma=0)$, firms act according to hypothesis 1 and cut wages by (at least) 10 points. If workers care to some degree about reference points $(0<\gamma<10)$, workers trade off the loss of utility that is due to the violation of the reference point and the loss of utility that is due to increased advantageous inequality (caused by a decrease in effort that would offset the first loss of utility). In this case, depending on the workers $\gamma$ and $\beta$ it is possible that some worker's do not punish small but only larger wage cuts. Hence, I suggest an intermediate prediction that wages in CasRP should at least be more rigid than in BASE. Regarding effort: In case stable (or increased) wages are not reciprocated by higher effort, as predicted, workers overcompensate wage cuts by effort decreases $(\theta>1)$, leading to an effort decrease even when controlling for the wage level. But even when stable wages are rewarded, a reference-point effect is observed in CasRP since workers render wage cuts unprofitable in any case: Controlling for the wage level, wage cuts should be accompanied with relatively lower effort compared to stable wages.

An important aspect that has been neglected so far is that firms could anticipate that a high out-of-recession wage is problematic because it lowers payoffs in recession. Firms could react by paying lower wages (and hence foregoing earnings) out of recession and hence being able to pay lower wages (and hence gain earnings) also in recession. This kind of strategy is, however, suboptimal given the parameters of the experiment. ${ }^{25}$ Crucially, however, these strategies may become optimal for firms that also have preferences of the FS-type. In equilibrium, not cutting wages leads to disadvantageous inequality, lowering firms's utility compared to standard preferences. Lowering, however, the out-ofrecession wage leads to less disadvantageous inequality in recession. I do not make specific assumptions about the parameters for the inequity averse firms, but consider it as an open question whether out-of-recession wages in CasRP are already lower than in BASE. Additionally, the theory does not provide a clear-cut prediction under which circumstances initially concluded contracts serve as reference points, whether an explicit contract conclusion is necessary or not, or whether better information lead to more rigid wages or not.

Received: 30 October 2019 Accepted: 12 January 2021

Published online: 10 March 2021

\section{References}

Abeler, J., Altmann, S., Kube, S., Wibral, M.: Gift exchange and workers'fairness concerns: when equality is unfair. J. Eur. Econ. Assoc. 8, 1229-1324 (2010)

Abeler, J., Falk, A., Goette, L., Huffman, D.: Reference points and effort provision. Am. Econ. Rev. 101(2), 470-492 (2011)

Akerlof, G.: Labor contracts as partial gift exchange. Q. J. Econ. 97, 543-569 (1982)

Akerlof, G., Yellen, J.: The fair wage-effort hypothesis and unemployment. Q. J. Econ. 105, 255-283 (1990)

Azariadis, C.: Implicit contracts and underemployment equilibria. J. Polit. Econ. 83, 1183-1202 (1975)

Babcock, L., Loewenstein, G.: Explaining bargaining impasse: the role of selfserving biases. J. Econ. Perspect. 11(1), 109-126 (1997)

Baily, M.: Wages and employment under uncertain demand. Rev. Econ. Stud. 41, 37-50 (1974)

Bartling, B., Schmidt, K.M.: Reference points, social norms, and fairness in contract renegotiations. J. Eur. Econ. Assoc. 13(1), 98-129 (2014)

Bartling, B., von Siemens, F.: Wage inequality and team production: an experimental analysis. J. Econ. Psychol. 32(1), 1-16 (2011)

Barwell, R.D., Schweitzer, M.E.: The incidence of nominal and real wage rigidities in Great Britain: 1978-98. Econ. J. 177, F553-F569 (2007)

\footnotetext{
${ }^{25}$ Paying $w=84$ out of and in recession leads to earnings of $x_{F}=66$ and $x_{F}^{\text {Rec }}=46$ with a probability of $2 / 3$ and $1 / 3$ respectively. The best strategies available, in which the out of recession payment is reduced, lead to payoffs below this result. Paying $w=78$ out of and in recession (in order to (almost) equalize payoffs with an effort level of 9 with a slight worker's advantage) leads to earnings of $x_{F}=62$ and $x_{F}^{R e c}=52$ : A loss of 4 out of recession with a probability of $2 / 3$ and a gain of 6 in recession with a probability of $1 / 3$. Paying $w=71$ out of recession (in order to equalize payoffs with an effort level of 8 ) and paying $w=74$ in recession leads to payoffs of $x_{F}=59$ and $x_{F}^{R e C}=56$ : A loss of 7 out of recession with probability $2 / 3$ and a gain of 10 in recession with probability of $1 / 3$. Again, the low likelihood of recession makes this strategy suboptimal.
} 
Bauer, T., Bonin, H., Goette, L., Sunde, U.: Real and nominal wage rigidities and the rate of inflation: Evidence from west German micro data. Econ. J. 117, F508-F529 (2007)

Bewley, T.: Why Wages Don't Fall During a Recession. Havard University Press, Cambridge (1999)

Blinder, A., Choi, D.: A shred of evidence on theories of wage stickiness. Q. J. Econ. 105, 1003-1015 (1990)

Bolton, G.E., Karagözoglu, E.: On the influence of hard leverage in a soft bargaining game: the importance of credible claims. Games Econ. Behav. 99, 164-179 (2015)

Bracha, A., Gneezy, U., Loewenstein, G.: Relative pay and labor supply. J. Labor Econ. 33(21), 297-315 (2015)

Buchanan, J., Houser, D.: If wages fell during a recession. J. Econ. Behav. Organ. (2020). https://doi.org/10.1016/j.jebo.2020.09.023

Burda, M., Güth, W., Kirchsteiger, G., Uhlig, H.: Employment duration and resistance to wage reductions: experimental evidence. Homo Oeconomicus 22(2), 169-183 (2005)

Calmfors, L., Driffill, J.: Bargaining structure, corporatism and macroeconomic performance. Econ. Policy 3(6), 13-61 (1988)

Campbell, C., Kamlani, K.: The reasons for wage rigidity: evidence from a survey of firms. Q. J. Econ. 112, 759-789 (1997)

Charness, G., Cobo-Reyes, R., Jimenez, N., Lacomba, J.A., Lagos, F.: The hidden advantage of delegation: pareto improvements in a gift exchange game. Am. Econ. Rev. 102(5), 2358-2379 (2012)

Charness, G., Kuhn, P.: Does pay inequality affect worker effort? Experimental evidence. J. Labor Econ. 25(4), 693-723 (2007)

Charness, G., Levine, D.I.: Changes in the employment contract? Evidence from a quasi-experiment. J. Econ. Behav. Organ. 47, 391-405 (2002)

Charness, G., Rabin, M.: Understanding social preferences with simple tests. Q. J. Econ. 117(3), 817-869 (2002)

Chen, D.L., Horton, J.J.:The wages of pay cuts. Mimeo (2014)

Cohn, A., Fehr, E., Goette, L.: Fair wages and effort provision: combining evidence from a choice experiment and a field experiment. Manage. Sci. 61(8), 1777-1794 (2015)

Cohn, A., Fehr, E., Herrmann, B., Schneider, F.: Social comparison and effort provision: evidence from a field experiment. J. Eur. Econ. Assoc. 12(4), 877-898 (2014)

Devicienti, F., Maida, A., Sestito, P.: Downward wage rigidity in Italy: microbased measures and implications. Econ. J. 117, F530-F552 (2007)

Dickens, W.T., Goette, L., Groshen, E.L., Holden, S., Messina, J., Schweitzer, M.E., Turunen, J., Ward, M.E.: How wages change: micro evidence from the internation wage flexibility project. J. Econ. Perspect. 21(2), 195-214 (2007)

Dickson, A., Fongoni, M.: Asymmetric reference-dependent reciprocity, downward wage rigidity, and the employment contract. J. Econ. Behav. Organ. 163, 409-429 (2019)

Elsby, M.W., Shin, D., Solon, G.: Wage adjustment in the greate recession and other downturns: evidence from the united states and great britain. J. Labor Econ. 34(1), 249-291 (2016)

Falk, A., Fehr, E., Zehnder, C.: Fairness perceptions and reservation wagesthe behavioral effects of minimum wage laws. Q. J. Econ. 121 1347-1381 (2006)

Fehr, E., Goette, L.: Robustness and real consequences of nominal wage rigidity. J. Monetary Econ. 52, 779-804 (2005)

Fehr, E., Hart, O., Zehnder, C.: Contracts, reference points, and competitionbehavioral effects of the fundamental transformation. J. Eur. Econ. Assoc. 7(2-3), 561-572 (2009)

Fehr, E., Hart, O., Zehnder, C.: Contracts as reference points-experimental evidence. Am. Econ. Rev. 101(2), 493-525 (2011)

Fehr, E., Hart, O., Zehnder, C.: How do informal agreements and revisions shape contractual reference points? J. Eur. Econ. Assoc. 13(1), 1-28 (2015)

Fehr, E., Kirchler, E., Weichbold, A., Gächter, S.: When social norms overpower competition: gift exchange in experimental labor markets. J. Labor Econ. 16(2), 324-351 (1998)

Fehr, E., Kirchsteiger, G., Riedl, A.: Does fairness prevent market clearing? An experimental investigation. Q. J. Econ. 108, 437-459 (1993)
Fehr, E., Schmidt, K.: A theory of fairness, competition, and cooperation. Q. J. Econ. 114(3), 817-868 (1999)

Fischbacher, U.: z-Tree: Zurich toolbox for ready-made economic experiments. Exp. Econ. 10(2), 171-178 (2007)

Franke, J., Gurtoviy, R., Mertins, V.: Workers' participation in wage setting: a gift-exchange experiment. J. Econ. Psychol. 56, 151-162 (2016)

Furnham, A., Boo, H.C.: A literature review of the anchoring effect. J. SocioEcon. 40(1), 35-42 (2011)

Gächter, S., Riedl, A.: Moral property rights in bargaining with infeasible claims. Manage. Sci. 51(2), 249-263 (2005)

Gerhards, L., Heinz, M.: In good times and bad-reciprocal behavior at the workplace in times of economic crises. J. Econ. Behav. Organ. 134, 228-239 (2017)

Gintis, H.: The nature of labor market exchange and the theory of capitalist production. Rev. Rad. Polit. Econ. 8, 36-54 (1976)

Goette, L., Sunde, U., Bauer, T.: Wage rigidity: measurement, causes and consequences. Econ. J. 117, F499-F507 (2007)

Gordon, D.: A neo-classical theory of Keynesian unemployment. Econ. Inquiry 12, 431-459 (1974)

Greenberg, J.: Employee theft as a reaction to underpayment inequity: the hidden cost of pay cuts. J. Appl. Psychol. 75(5), 561-568 (1990)

Greenberg, J.: Stealing in the name of justice: informational and interpersonal moderators of theft reactions to unterpayment inequality. Organ. Behav. Hum. Decision Processes 54(1), 81-103 (1993)

Greiner, B.: An online recruitment system for economic experiements. In K. Kremer and V. Macho (Eds.), Forschung und wissenschaftliches Rechnen 2003. GWDG Bericht 63, 79-93 (2004)

Hannan, L.: The combined effect of wages and firm profit on employee effort. Account. Rev. 80(1), 167-188 (2005)

Hart, O., Moore, J.: Contracts as reference points. Q. J. Econ. 123(1), 1-48 (2008)

Herweg, F., Schmidt, K.M.: Loss aversion and inefficient renegotiation. Rev. Econ. Stud. 82(1), 297-332 (2015)

Kahneman, D., Knetsch, J.L., Thaler, R.: Fairness as constraint on profit seeking: entitlements in the market. Am. Econ. Rev. 76(4), 728-741 (1986)

Kaur, S.: Nominal wage rigidity in village labor markets. Am. Econ. Rev. 109(10), 3585-3616 (2018)

Kocher, M., Strasser, S.: The fair employment hypothesis: reciprocity in unstable environments. Mimeo (2011)

Kube, S., Maréchal, M.A., Puppe, C.: Do wage cuts damage work morale? Evidence from a field experiment. J. Eur. Econ. Assoc. 11(4), 853-870 (2013)

Lee, D., Rupp, N.G.: Retracting a gift: how does employee effort respond to wage redution? J. Labor Econ. 25(4), 725-761 (2007)

Lindbeck, A., Snower, D.: The Insider-Outsider Theory of Employment and Unemployment. MIT Press, Cambridge, Mass (1988)

Mas, A.: Pay, reference points, and police performance. Q. J. Econ. 121(3), 783-821 (2006)

Mortensen, D.: Job search and labor market analysis. In: Ashenfelter, O., Layard, R. (eds.) Handbook of Labor Economics, Volume, vol. 2. North-Holland, Amsterdam (1986)

Ockenfels, A., Sliwka, D., Werner, P.: Bonus payments and reference point violations. Manage. Sci. 61(7), 1496-1513 (2015)

Owens, M., Kagel, J.: Minimum wage restrictions and employee effort in incomplete labor markets: an experimental investigation. J. Econ. Behav. Organ. 73(3), 317-326 (2010)

Rabin, M.: Incorporating fairness into game theory and economics. Am. Econ. Rev. 83(5), 1281-1302 (1993)

Riedl, A., Tyran, J.-R.: Tax liability side equivalence in gift-exchange labor markets. J. Public Econ. 89, 2369-2382 (2005)

Shafir, E., Diamond, P., Tversky, A.: Money illusion. Q. J. Econ. 112(2), 341-374 (1997)

Shapiro, C., Stiglitz, J.: Equilibrium unemployment as a worker discipline devise. Am. Econ. Rev. 74, 433-444 (1984)

\section{Publisher's Note}

Springer Nature remains neutral with regard to jurisdictional claims in published maps and institutional affiliations. 